\title{
Renda e Migração na Região Metropolitana de Belo Horizonte
}

\author{
Thiago Canettieri *
}

As migrações intrametropolitanas representam importante elemento de análise para compreensão da expansão urbana das metrópoles brasileiras. Essas trocas demográficas, entre núcleo e periferia de uma mesma região metropolitana, contribuíram para consolidar o padrão de periferização da população metropolitana, bem como para consolidar essas regiões.

Existe vasta literatura sobre migrações e tópicos correlatos já que a necessidade de se conhecer os movimentos populacionais é de primeira ordem. Podendo se desenvolver nas mais variadas escalas, o processo migratório de mudança de domicílio representa uma área cara à demografia e outras ciências que tratam de compreendê-lo.

O artigo tem por objetivo apresentar a análise da função que a renda desempenha na decisão da migração intrametropolitana no contexto da Região Metropolitana de Belo Horizonte (RMBH), abarcando os trinta e quatro municípios integrantes.

Neste artigo, postula-se como hipótese que os migrantes que se deslocam para a cidade principal têm maior renda que os emigrantes. Isso se deve não apenas à estrutura financeira do indivíduo, mas, principalmente, à organização socioeconômica espacial da região metropolitana. A cidade principal, Belo Horizonte, é conformada como importante área central, com preços de imóveis

\footnotetext{
* Mestrando em Geografia - Tratamento da Informação Espacial da Pontifícia Universidade Católica de Minas Gerais.
} 
(tanto da terra como das benfeitorias) elevados, bem como um custo de vida elevado (TONUCCI, MAGALHÃES, SILVA, 2012). Dessa forma, pessoas de baixa renda não possuem capacidade financeira para manter-se em Belo Horizonte, e acabam migrando. Em contrapartida, pessoas que residiam em outros municípios que obtiveram um aumento na renda conseguem realizar o movimento em direção à cidade de Belo Horizonte.

Estudos que buscaram relacionar a renda com os processos migratórios (em diferentes escalas) são recorrentes na literatura sobre o tema (VANDERKAMP, 1971; MICHAELIDES, 2009; KENNAN; WALKER, 2009; TODARO, 1969). Nesses estudos, a variável renda ora é considerada como uma generalização - como em Vanderkamp (1971) em que é considerada a renda média das regiões - ora é considerada como uma expectativa - como em Kennan e Walker (2009) em que consideram a renda esperada. No entanto, a presente pesquisa, ao analisar a variável renda, pretende relacioná-la não à condição do indivíduo, mas à estrutura socioespacial metropolitana que organiza a distribuição espacial da população. Dessa forma, a renda do indivíduo (renda domiciliar per capita) é analisada no estudo estando relacionada à direção do fluxo migratório intrametropolitano. Nesse sentido, um estudo semelhante foi desenvolvido por Peeters (2009) para a Bélgica, constatando que existia uma tendência de determinados locais atraírem ou repelirem determinados pessoas pelo nível de renda.

Para isso, a metodologia desenvolvida simplifica esse processo de movimento. Agrupamos a direção dos fluxos migratórios em três categorias: 1) Da cidade principal (Belo Horizonte) para a periferia (outros municípios da RMBH); 2) Da periferia para a cidade principal; 3) Da periferia para a periferia. É, de fato, uma ampla generalização para tratar os dados, mas nesse primeiro momento de um estudo exploratório, a mesma servirá para fornecer subsídios para uma análise também geral dos padrões encontrados e, assim, espera-se desenvolver novas metodologias para novos estudos mais específicos, explorando características locais e agregando à análise outras dinâmicas.

Para esta análise foram utilizadas as informações de migração de data fixa, que se refere ao indivíduo que em uma data pré-determinada estava residindo em um município diferente do que residia na data do Censo. Esta escolha de variável se deve ao fato de que no Censo de 2000 o quesito sobre migração de última etapa não foi incluído. Assim, os dados trabalhados de 1991 e de 2010 são, para efeito de comparação, também referentes à migração de data fixa.

A informação referente à renda foi obtida através da variável que apresenta o rendimento total do domicílio per capita. Desta forma, é possível evitar, em grande medida, situações em que existem dependentes da renda de um ou mais indivíduos. Considera-se a renda de todo o domicílio, dividida pelo número de moradores.

Cabe destacar algumas limitações nos dados para o desenvolvimento da pesquisa que devem ser explicitadas e levadas em consideração na análise e 
discussão dos resultados. As informações censitárias não oferecem a possibilidade de se conhecer as características dos migrantes no momento do movimento. José Marco Cunha (1993, p.166) já chamou a atenção para essa situação e, em suas palavras, "[...] qualquer análise sobre a condição do migrante do momento da migração feita a partir dos censos é, em maior ou menor grau, um exercício de aproximação e até mesmo inferência." Também a metodologia adotada simplifica muito a realidade, e pode-se perder alguns movimentos migratórios entre os municípios de menor expressão.

Cunha (1993, p.163) afirma que durante muito tempo a demografia preocupou-se com movimentos migratórios interestaduais e produziu importante material analítico e teórico, enquanto que o tema da migração intrametropolitana "[...] praticamente não se produziu". No entanto, segundo o autor, o tema ganhou força a partir do final dos anos de 1980. Ressalta ainda que a migração intrametropolitana continuará assumindo um papel fundamental na determinação da dinâmica demográfica.

\section{A renda e o processo migratório}

A migração acontece por vários motivos, mas a renda assume um papel central na determinação das direções dos fluxos, na seletividade e na retenção dos migrantes. A ideia aparece, segundo Lucas (1997), no trabalho de Sjaastad (1962) que postulou que a decisão de migração é influenciada pelo valor da diferença das fontes de renda entre os locais alternativos, menos qualquer renda inicial ou subsequente dos custos das mudanças. Dessa maneira, a migração é uma forma de investimento. Todaro (1969) desenvolveu e aprofundou a hipótese de Sjaastad. A hipótese para esses movimentos, segundo Todaro (1969), diz respeito aos ganhos esperados, que incluem o aumento dos ganhos no local de imigração e/ou a redução das perdas no local de emigração. Diversos estudos empíricos vieram em seguida e forneceram evidências que sustentam este modelo, como o de Lucas (1988), Todaro (1976) e Zhu (2002). Assim, dentro dos mais variados ganhos e perdas, a renda assume hoje papel primordial, em especial por determinar tantos outros fatores, como moradia, alimentação, consumo, transporte, etc.

Kennan e Walker (2009) trabalharam com um modelo estrutural dinâmico que avalia as decisões de migração em sequência nos Estados Unidos e constataram que a principal influência está na renda esperada, considerando os custos de movimentação e de fixação. Michaelides (2009) também adiciona, além de uma renda bruta esperada - por exemplo, o salário - que a decisão migratória está ligada ao custo de vida, muitas vezes ligado ao custo da habitação. Assim, o autor afirma que a probabilidade de um indivíduo migrar aumenta de acordo com a diferença de salários no destino e na origem, enquanto é reduzida de acordo com a diferença do custo de habitação no destino e na origem. A renda, segundo Vanderkamp (1971), assume dupla importância nos estudos migratórios. Ela 
determina as possibilidades de um modo de vida, padrão de consumo - inclusive de habitação - e de um leque de escolhas no processo migratório. Sua outra função reside no custo do deslocamento. Migrar envolve um custo determinado e só é possível fazê-lo quando a renda é suficiente para financiar o movimento.

Toda esta literatura concentra-se numa abordagem demográfica descendente da economia neoclássica, que se foca nas estruturas individuais. No entanto, para se compreender a estrutura social das metrópoles contemporâneas, a distribuição espacial da população e como esta se organiza através dos fluxos, é necessário empreender uma análise que considere a estrutura socioespacial que organiza a metrópole.

Segundo Brito (2006), a perspectiva socioeconômica do processo decisório das migrações intraurbanas está baseada na hipótese de que os deslocamentos são respostas às estratégias de grandes agentes estruturais do sistema capitalista (proprietários de terra e dos meios de produção e o Estado) que atuam de forma a promover a acumulação de capital, o que implica no deslocamento das populações para servirem a esta lógica.

Assim, deve-se entender a migração como determinada por uma força externa: a estrutura econômica. Toda mobilidade no capitalismo, escreve Gaudemar, é uma mobilidade forçada. Em suas palavras

Com a mobilidade do trabalho manifesta-se sempre o
modo como os homens submetem o seu comportamento
às exigências do crescimento capitalista. Toda estratégia
capitalista de mobilidade é, igualmente, estratégia de
mobilidade forçada (1977, p.18).

A mobilidade dos trabalhadores no momento atual deve ser pensada em dois momentos: 1) o momento da utilização da força de trabalho; 2) o momento de reprodução da força de trabalho.

O primeiro, analisado em profundidade por Gaudemar (1977), diz respeito ao momento da submissão da mobilidade do trabalhador às exigências do capital. O movimento é sempre em direção ao trabalho e, justifica uma série de fluxos migratórios e de outros tipos de mobilidade humana. É esta mobilidade que permite a mobilização da força de trabalho para produzir as mercadorias. O segundo momento, da reprodução das forças de trabalho, é o momento do trabalhador fora do momento do trabalho que deve garantir sua reprodução material. Diz respeito aos movimentos em busca de moradia e recursos para a sobrevivência, condicionados pelo padrão de vida que devem manter.

As necessidades criadas pela lógica do capitalismo no que tange ao mercado de trabalho podem ser satisfeitas a partir da mobilidade do trabalho. Desta maneira, em termos da economia política, todos os fluxos migratórios são, de alguma maneira, lucrativos (mas não no sentido atribuído pelos neoclássicos 
de maximização dos benefícios pelos agentes). Os deslocamentos espaciais têm como finalidade última a "valorização do capital" (GAUDEMAR, 1977, p.21).

Além da escala estrutural, deve-se entender também a mobilidade da perspectiva geográfica. A mobilidade acontece devido a produção dos espaços de forma desigual. A produção do espaço no capitalismo pressupõe a desigualdade entre os espaços. Determinada área, por diversos motivos, desenvolve-se mais do que outras. E isso pode ocorrer nas mais variadas escalas; entre países ou entre bairros. Assim sendo, a população que reside ou que trabalha deve ser, de algum modo, coerente com esta forma de desenvolvimento, balizado através da economia de mercado: o acesso se dá a partir do controle da "mão invisível" do mercado. Também, ao mesmo tempo, a mobilidade constitui-se como estratégia para perpetuar a produção desigual dos espaços. Os fluxos criados e mantidos por esta lógica de mercado agravam ainda mais a desigualdade, pois tendem a uma concentração das riquezas socialmente produzidas, não apenas socialmente, mas geograficamente.

\section{A função da renda nas decisões migratórias intrametropolitanas na RMBH}

Os dados das migrações realizadas pelos indivíduos dentro da Região Metropolitana de Belo Horizonte registrados no censo de 1991, 2000 e 2010 são apresentados a seguir.

\begin{tabular}{|ccc|ccc|cc|}
\hline \multicolumn{8}{|c|}{ TABELA 1 } \\
Migrantes Intrametropolitanos de Data Fixa - Anos de & $\mathbf{1 9 9 1 , 2 0 0 0}$ e 2010 \\
\hline $\begin{array}{c}\text { Migrantes } \\
\text { Intrametropolitanos }\end{array}$ & $\mathbf{1 9 9 1}$ & \multicolumn{2}{c|}{$\mathbf{2 0 0 0}$} & \multicolumn{2}{c|}{$\mathbf{2 0 1 0}$} \\
& Absoluto & $\%$ & Absoluto & $\%$ & Absoluto & $\%$ \\
\hline Migrantes de Data & 169.826 & 100 & 225.282 & 100 & 184.030 & 100 \\
Fixa & & 120.863 & 71,2 & 141.136 & 62,7 & 107.136 & 58,2 \\
Núcleo-Periferia & 8.650 & 5,1 & 17.228 & 7,6 & 15.316 & 8,3 \\
Periferia-Núcleo & 40.313 & 23,7 & 66.918 & 29,7 & 61.578 & 33,5 \\
Periferia-Periferia & &
\end{tabular}

Fonte dos dados: IBGE, 1991, 2000 e 2010 - Elaboração: Thiago Canettieri.

A análise dos dados revela que os fluxos migratórios apresentam um aumento no período entre 1991 e 2000 e um decréscimo entre os anos de 2000 e 2010. Mas, deve ser salientando que, mesmo com a queda nos valores absolutos, os números de migrantes intrametropolitanos do ano de 2010 são superiores ao de 1991. Em termos relativos, observa-se que a participação de cada fluxo migratório é mais ou menos regular, embora se observe uma 
queda de 13 pontos percentuais de 1991 a 2010 no sentido Núcleo-Periferia e o consequente aumento de $10,2 \%$ no fluxo entre as periferias. De tal maneira, deve ser destacada a importância da migração no sentido periferia-periferia para a composição das migrações intrametropolitanas recentes. Passando a representar um terço dos fluxos intrametropolitanos, esses resultados apontam para o aumento da importância das trocas populacionais no interior da periferia metropolitana nos processos de redistribuição espacial da população.

A direção dos fluxos é uma informação substancial para a análise pretendida. Observa-se que em todos os períodos a migração no sentido núcleo (cidade de Belo Horizonte) para as periferias (outros municípios da RMBH) é dominante sobre os outros sentidos. Assim, pode-se afirmar que o saldo migratório intrametropolitano de Belo Horizonte, nos três Censos em análise, é negativo.

A tabela 2 apresenta a diferença da renda média dos migrantes intrametropolitanos e dos não migrantes.

\section{TABELA 2}

Renda Média dos Migrantes Intrametropolitanos de Data Fixa e Não Migrantes - Anos de 2000 e 2010

\begin{tabular}{|c|c|c|c|c|c|c|c|}
\hline \multirow{2}{*}{$\begin{array}{l}\text { Renda } \\
\text { Média }\end{array}$} & \multicolumn{2}{|c|}{ RMBH } & \multicolumn{2}{|l|}{ Núcleo } & \multicolumn{3}{|c|}{ Periferia } \\
\hline & Migrante & $\begin{array}{c}\text { Nào } \\
\text { Migrante }\end{array}$ & $\begin{array}{c}\text { Migrante para a } \\
\text { Periferia }\end{array}$ & $\begin{array}{c}\text { Não } \\
\text { Migrante }\end{array}$ & $\begin{array}{c}\text { Migrante para o } \\
\text { Núcleo }\end{array}$ & $\begin{array}{c}\text { Migrante para } \\
\text { Periferia }\end{array}$ & $\begin{array}{c}\text { Não } \\
\text { Migrante }\end{array}$ \\
\hline 2000 & 429,24 & 599,38 & 349,61 & 882,86 & 377,27 & 227,76 & 300,82 \\
\hline 2010 & $1.022,23$ & $1.324,02$ & $1.508,08$ & $1.978,88$ & $1.335,82$ & 753,72 & 846,56 \\
\hline
\end{tabular}

Fonte dos dados: IBGE, 2000 e 2010 - Elaboração: Thiago Canettieri

Observa-se que, de um modo geral, os indivíduos migrantes da RMBH possuem uma renda inferior ao indivíduo não migrante, com exceção dos migrantes que realizaram o movimento no sentido periferia - núcleo, tanto no ano de 2000 como no ano de 2010. Embora a renda média tenha aumentado de forma considerável, a diferença da renda entre os migrantes e não migrantes da Região Metropolitana de Belo Horizonte quase duplicou no período.

Quando se considera os migrantes que realizaram o movimento da cidade núcleo para a periferia metropolitana observa-se que a diferença de renda com o não migrante é ainda maior nos dois anos analisados. Embora a diferença diminua no período, deve ser destacado que ainda é a maior diferença. Isso significa que as pessoas que saem de Belo Horizonte possuem renda muito inferior daquelas que continuam a residir.

Passando a analisar o movimento migratório da periferia para o núcleo a situação é inversa às duas anteriores. A renda média dos migrantes é mais elevada do que a dos não migrantes para o ano de 2000 e de 2010. Pode-se considerar que, para realizar este tipo de migração é necessário um maior investimento financeiro, por diversos motivos, como o elevado custo de moradia e de vida em 
Belo Horizonte como demonstrado por Tonnuci, Magalhães e Silva (2012). Devese salientar ainda que a diferença de renda entre os migrantes e não migrantes neste deslocamento aumentou mais de seis vezes no período de dez anos.

A análise dos dados referente ao fluxo migratório na direção núcleo-periferia e na direção periferia-núcleo revela importante dinâmica metropolitana da RMBH. O município núcleo, Belo Horizonte, vivencia um processo de elitização em duplo sentido. A população que sai do município é de uma renda média inferior à renda média dos não migrantes e, os imigrantes provenientes dos outros municípios metropolitanos possuem renda média acima dos não migrantes residentes na periferia.

Outro aspecto importante a ser considerado nas análises migratórias intrametropolitanas contemporâneas diz respeito aos deslocamentos periferiaperiferia. Os dados demonstram que a renda média do migrante, para ambos os anos em análise, é inferior à do não migrante. Ainda, entre 2000 e 2010, esta diferença aumentou, o que revela que a maior parte desses movimentos são realizados por populações de rendimentos reduzidos.

Este processo é ainda explorado na análise dos gráficos a seguir, os quais demonstram o número dos migrantes no sentido núcleo-periferia e periferianúcleo por faixas de renda domiciliar per capita. Nos gráficos é possível verificar as diferenças de direção do processo migratório variando de acordo com a renda.

GRÁFICO 1

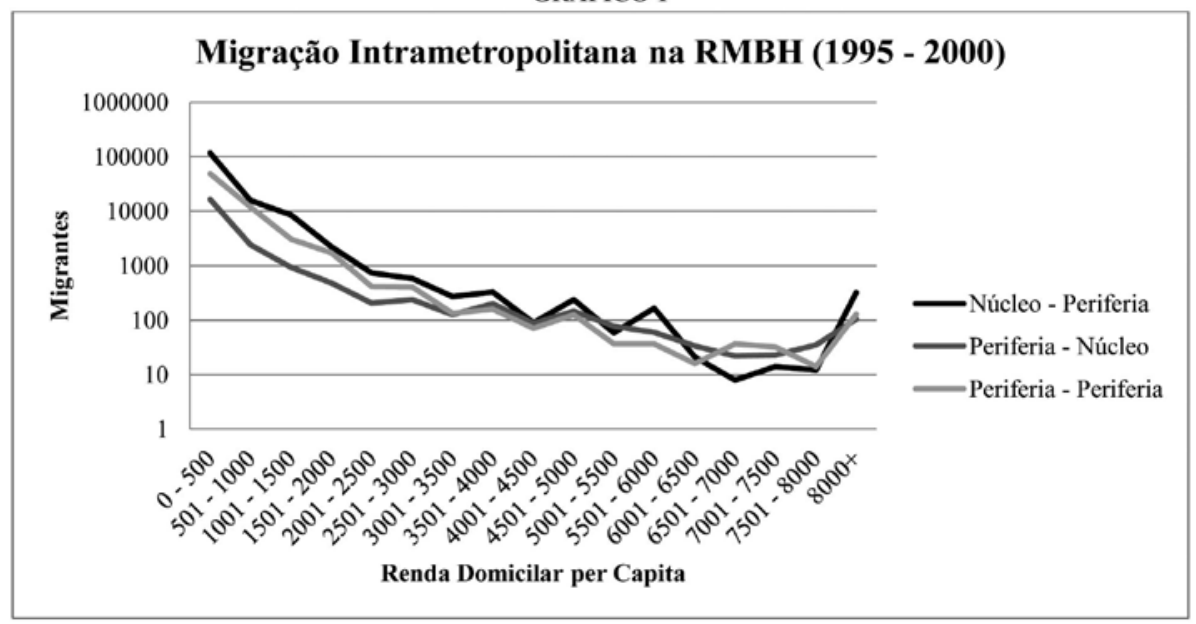

Fonte dos dados: IBGE, 2000 - Elaboração: Thiago Canettieri

O gráfico referente ao Censo de 2000 demonstra que existiu um maior volume de pessoas de renda entre zero e quinhentos reais realizando movimentos migratórios intrametropolitanos. Desses movimentos, o predominante acontece no sentido núcleo-periferia, embora existam valores ainda relativamente altos nos outros tipos de movimento em análise. 
Para seguir na análise do gráfico, vamos observá-lo a partir de três recortes. 0 primeiro, partindo do início até a faixa de renda domiciliar per capita de $\mathrm{R} \$ 3.501$ a $\mathrm{R} \$ 4.000$, demonstra um saldo migratório negativo da cidade núcleo. Observase um hiato considerável entre a curva que representa o fluxo migratório do núcleo para a periferia e a curva referente ao movimento contrário, da periferia para o núcleo. No segundo recorte, compreendido entre as faixas de renda de R\$ 4.001 e $R \$ 6.000$, o saldo migratório aproxima-se de zero, revelando que existe uma aproximação entre o número dos que saem e dos que entram na cidade principal. No recorte seguinte, a partir da faixa de renda de $R \$ 6.001$ a $R \$ 6,500$, observamos um novo hiato - embora o espaço entre as curvas seja menor que no primeiro. Este indica que existe um maior número de pessoas entrando na capital do que saindo.

O movimento entre os municípios da periferia também é concentrado em populações de renda mais baixa, diminuindo a frequência do movimento de acordo com o incremento da renda, sem, no entanto, deixar de existir.

O gráfico referente ao ano de 2010 apresenta, em linhas gerais, o padrão das linhas muito semelhante ao encontrado no gráfico para o ano do Censo anterior, no entanto, existem diferenças substanciais no padrão, além da alteração do volume dos movimentos migratórios.

GRÁFICO 2

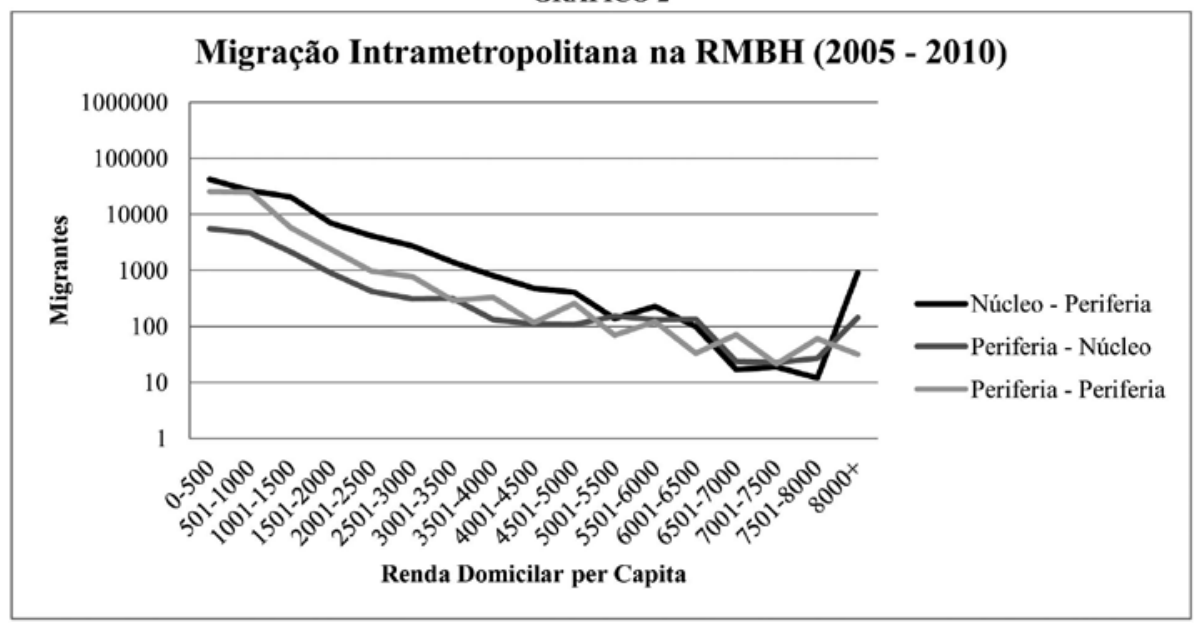

Fonte dos dados: IBGE, 2000 - Elaboração: Thiago Canettieri

O gráfico revela que o número de movimentos é, novamente, concentrado na população com as faixas de renda domiciliar mais baixas. Para o ano de 2010 é perceptível que o hiato entre os indivíduos que são provenientes do núcleo para a periferia aumenta em relação aos que fazem o movimento dos 
municípios da periferia para o núcleo. Além deste aumento da distância entre as linhas, observa-se também um prolongamento dessa característica das curvas, chegando a predominar até a faixa de renda de $R \$ 4.501$ a $R \$ 5.000$. A secção do gráfico seguinte, que representa a aproximação de um saldo migratório próximo de zero, compreende as faixas de renda entre $R \$ 5.001$ até $R \$ 7.500$. Por fim, a última seção que representou no gráfico anterior um saldo migratório positivo para o núcleo, com um maior número absoluto de imigrantes do que de emigrantes, é para o ano de 2010 muito tímido, abrangendo apenas a faixa de renda entre $R \$ 7.501$ e $R \$ 8.000$. Destaca-se, por fim, que a faixa de renda superior a $\mathrm{R} \$ 8.000$ volta a apresentar um aumento no número de pessoas que realizaram o movimento no sentido núcleo-periferia. Isso se deve a uma maior extensão e consolidação dos chamados condomínios fechados, fora do município central da região metropolitana, mas relativamente próximos.

O movimento que acontece entre os municípios da periferia tem padrão semelhante ao visualizado em 2000, movimento esse concentrado entre a população de renda mais baixa e que tende a reduzir, ao passo que a renda domiciliar por pessoa aumenta.

\section{Considerações finais}

As migrações intrametropolitanas são elementos primordiais para a compreensão do processo de metropolização e expansão urbana, agindo de forma a aprofundar a interação entre os municípios. No caso da RMBH, os fluxos migratórios intrametropolitanos apresentam crescimento entre 1991 e 2000 e decrescem entre o censo de 2000 e 2010, mas, mesmo com o declínio o valor absoluto de 2010 permaneceu superior ao do Censo de 1991.

A análise por estratos da renda oferece importantes subsídios para ampliar tal compreensão do processo de metropolização. Os dados descritos no presente trabalho demonstram a existência de uma clara segregação nos movimentos migratórios.

A maior parte das migrações intrametropolitanas na RMBH é realizada por população de renda mais baixa, e com um claro padrão espacial. Um maior volume de pessoas de renda inferior realiza o movimento com destino à periferia, partindo tanto do município núcleo, Belo Horizonte, como também de outros municípios da periferia. $O$ crescimento populacional da periferia metropolitana se deve, em grande medida, ao fluxo migratório intenso direcionado a este espaço. Esta reorganização espacial da população é produzida por uma série de processos, próprios da cidade capitalista. Observa-se, nessas cidades, a tendência à privatização da cidade, acompanhada do processo de especulação imobiliária que, por sua vez, diminui as possibilidades de fazer valer a função social da propriedade urbana, processo que, em paralelo ao padrão de localização espacial dos programas de habitação popular, atua na redistribuição espacial da 
população de baixa renda, deslocando-a para as periferias na medida em que as áreas centrais são destinadas à especulação, ao capital e à classe abastada.

A tendência à centralidade da classe abastada pode ser visualizada também nos gráficos discutidos. A curva referente aos movimentos da periferia para o núcleo, referente a ambos os anos, apenas ultrapassa a de emigração do núcleo quando a renda está na faixa de $\mathrm{R} \$ 6.500,00$.

Como foi salientado, o padrão de redistribuição espacial da população encontrado não deve ser entendido como resultado da estrutura financeira do indivíduo, mas sim como da organização socioeconômica da região metropolitana e de sua produção enquanto tal. É assim que diversos autores abordam a questão, entre eles, Milton Santos (1980), Carlos Vainer (2000) e Ermínia Maricato (2000), o que não elimina, porém, a necessidade de trabalhos empíricos que comprovem e demonstrem tal processo, como no caso deste estudo referente à RMBH. É mister, todavia, que as pesquisas se estendam a outras metrópoles brasileiras e latino-americanas a fim de verificar a existência de padrões migratórios semelhantes.

\section{Referências}

BRITO, F. O Deslocamento da População Brasileira para as Metrópoles. Estudos Avançados, São Paulo, n. 57, p. 221-236, maio/ago. 2006.

BRITO, F. Urbanização, Metropolização e Mobilidade Espacial da População: Um breve ensaio além dos números. In: Taller Nacional Sobre Migración Interna y Desarrollo en Brasil: Diagnóstico, perspectivas y políticas. Comision Económica para América Latina y el Caribe, 2007.

BRITO, F; SOUZA, J. A Metropolização da Pobreza. In: XI Encontro Nacional de Estudos Populacionais. Caxambu: ABEP, 1998.

CADWALLADER, M. Migration and Residential Mobility: Macro and Micro Approaches. Madison: University of Wisconsin Press, 1992.

CANETTIERI, T; LIBERATO, R. de C.; PEREIRA, T. Exclusão e Expulsão na Região Metropolitana de Belo Horizonte. In: Anais do XII Seminário Internacional Iberoamericano da Rede de Investigadores sobre Globalização e Território. Belo Horizonte: RII, 2012.

CARVALHO, J. A. M.; RIGOTTI, J. I. R. Os dados censitários brasileiros sobre migrações internas: algumas sugestões para análise. Revista Brasileira de Estudos Populacionais, Campinas, v.15, n.2, jun./dez. 1998.

CUNHA, J. M., DEDECCA, C. Migração e trabalho na Região Metropolitana de São Paulo nos anos 90: uma abordagem sem preconceito. Revista Brasileira de Estudos de População. Campinas, v.17, n.1/2, jun./dez. 2001.

CUNHA, J. M. A mobilidade intra-regional no contexto das mudanças no padrão migratório nacional: o caso da Região Metropolitana de São Paulo. In: X Encontro Nacional de Estudos Populacionais. Caxambu: ABEP, 1996.

CUNHA, J. M. Mobilidade intrametropolitana: Questões Metodológicas para o seu estudo. Revista Brasileira de Estudos Populacionais. Campinas, v.10, n.1/2, jun./dez. 1993. 
GAUDEMAR, Jean-Paul de. Mobilidade do Trabalho e Acumulação de Capital. Lisboa: Estampa, 1977.

GOLGHER, A. B. Fundamentos da migração. In: Texto para Discussão no 231. Belo Horizonte: CEDEPLAR/UFMG, 2004. Disponível em: <http://face.ufmg.br/cedeplar/td/TD2023/>. Acesso em: 2 fev. 2014.

GRAVES, P. Income and Migration Revisited. In: Munich Personal RePEc Archive Paper. 2010. Disponível em: <http://mpra.ub.uni-muenchen.de/19910/>. Acesso em: 4 fev. 2014.

KENNAN, J.; WALKER, J. The Effect of Expected Income on Individual Migration Decisions. Journal of the Econometric Society, Cambridge - MA, n.77, v.5, sept. 2009.

KENNAN, J.; WALKER, J. The Effect of Expected Income on Individual Migration Decisions. In: National Bureau of Economic Research. Working Paper Series, no 9585, 2008. Disponível em: <http://nber.org/papers/w9585/> Acesso em: 4 fev. 2014.

LEE, E. A Theory of Migration. Demography, vol.3, n.1, p. 47-57, sept./dec. 1966.

LUCAS, R. Internal Migration in Developing Countries. In: ROSENWEIG, Mark; STARK, Oded. Handbook of Population and Family Economics. London: Elsevier Science, 1997.

LUCAS, R. Migration from Botswana. Economic Journal, Londres, n. 95, mar. 1988.

MARICATO, E. As ideias fora do lugar e o lugar fora das ideias - Planejamento urbano no Brasil. In: ARANTES, O.; VAINER, C.; MARICATO, E. A Cidade do Pensamento Único: Desmanchando consensos. Petrópolis: Ed. Vozes, 2000.

MARTINE, G. Adaptação dos migrantes ou sobrevivência dos mais fortes? In: MOURA, H. A. (Org.) Migração interna: textos selecionados. Fortaleza: BNB, 1980.

MICHAELIDES, M. The effect of local ties, wages and housing costs on migration decisions. In: Munich Personal RePEc Archive Paper. 2009. Disponível em: <http://mpra.ub.unimuenchen.de/20379/> Acesso em: 4 fev. 2014.

PEETERS, L. Selective in-migration and income convergence and divergence across Belgian municipalities. Journal of Regional Studies, Seaford, v. 42, nov. 2009.

PLANE, D. Geographical Pattern Analysis of Income Migration in the U.S. International Journal of Population Geography, St. Andrews, v. 5, july/aug. 1999.

RAVENSTEIN, E. G. As leis da migração. In: MOURA, H. A. (Org.). Migração interna: textos selecionados. Fortaleza: BNB, 1980.

SANTOS, M. A Urbanização Desigual. São Paulo: Hucitec, 1980.

SJAASTAD, Larry. The Costs and Returns of Human Migration. Journal of Political Economy, Chicago, v.70, oct. 1962.

TODARO, M. A model of labour migration and urban unemployment in less developed countries. American Economic Review, New Haven, n.59, v.1, apr. 1969.

TODARO, M. Internal Migration in Development Countries: A Review of Theory, Evidence, Methodology and Research Priority. Genebra: BIT, 1976.

TONUCCI, J. B.; MAGALHÃES, F. N.; SILVA, H.. Valorização Imobiliária e Produção do Espaço: Novas frentes na RMBH. In: MENDONÇA, J.; COSTA, H. Estado e Capital Imobiliário: Convergências atuais na produção do espaço urbano brasileiro. Belo Horizonte: C/Arte, 2011. 
VAINER, C. Pátria, Empresa e Mercadoria - Notas sobre a estratégia discursiva do planejamento estratégico urbano. In: ARANTES, O.; VAINER, C.; MARICATO, E. A Cidade do Pensamento Único: Desmanchando Consensos. Petrópolis: Ed. Vozes, 2000.

VANDERKAMP, J. Migration Flows, their determinants and the effect of return migration. Journal of Political Economy, Chicago, v.79, n.5, mar. 1971.

ZHU, N. The Impacts of Income Gaps on Migration decisions in China. China Economic Review, Pequim, n. 13, mar./june 2002.

\title{
RESUMO
}

As migrações intrametropolitanas representam importante elemento de análise para compreensão da expansão urbana das metrópoles brasileiras. Este artigo tem por objetivo apresentar a análise da função que a renda desempenha na decisão da migração intrametropolitana no contexto da Região Metropolitana de Belo Horizonte (RMBH). Com base nas informações censitárias disponibilizadas pelo IBGE para os Censos de 2000 e 2010 foram consideradas as migrações no contexto interno da região metropolitana, sendo considerado o fluxo migratório da cidade principal (Belo Horizonte) para os outros municípios e o fluxo dos outros municípios para a cidade principal, organizando as informações de acordo com a renda. Os resultados encontrados tanto para 2000, quanto para 2010, mostram que Belo Horizonte experimenta saldos migratórios diferentes, que variam de acordo com a renda.

Palavras-chave: migração intrametropolitana; faixas de renda; Região Metropolitana de Belo Horizonte.

\begin{abstract}
The intrametropolitan migration represents an important element of analysis for understanding urban expansion of Brazilian metropolises. This article aims to present the analysis of the role played by the income in the intrametropolitan migration decision in the context of Belo Horizonte Metropolitan Region. Based in IBGE census information in 2000 and 2010, internal migration flows were considered from the metropolitan main town (Belo Horizonte) to the other municipalities, as well as in the opposite sense, organizing information according to income. The results both for 2000 and 2010 shows that Belo Horizonte has different migratory balances that vary with income.
\end{abstract}

Keywords: intrametropolitan migration; income class; Belo Horizonte Metropolitan Region. 